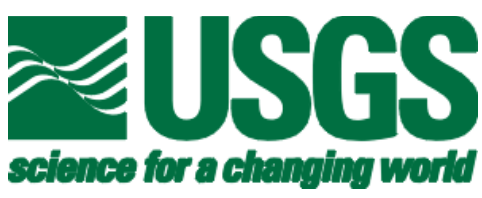

\title{
Surficial Geology of Lower Comb Wash, San Juan County, Utah
}

By Claire I. Longpré ${ }^{1}$

Open-File Report 01-424

2001

This report is preliminary and has not been reviewed for conformity with U.S. Geological Survey editorial standards or with the North American Stratigraphic Code. Any use of trade, firm, or product names is for descriptive purposes only and does not imply endorsement by the U.S. Government.

\section{U.S. DEPARTMENT OF THE INTERIOR}

U.S. GEOLOGICAL SURVEY

${ }^{1}$ U.S. Geological Survey, 1201 Pacific Ave. Suite 600, Tacoma, WA 98402 clongpre@usgs.gov 


\title{
DIGITAL DATABASE DESCRIPTION FOR THE SURFICIAL GEOLOGIC MAP OF LOWER COMB WASH, SAN JUAN COUNTY, UTAH
}

\author{
By Claire I. Longpré
}

\section{INTRODUCTION}

This digital map database, compiled from new mapping by the author, represents the general distribution of surficial deposits in lower Comb Wash. Together with the accompanying text file (readme.doc, readme.pdf, readme.txt, cw_pamph.doc, cw_pamph.pdf), it provides current information on the late Quaternary stratigraphy of the area covered. The database delineates map units that are identified by general age and lithology following the spatial resolution (scale) of the database to 1:12,000 or smaller. The content and character of the database, as well as three methods for obtaining the database, are described below.

\section{A NOTE FOR THOSE WHO DON'T USE DIGITAL GEOLOGIC MAP DATABASES}

Two sets of plotfiles containing images of much of the information in the database are available to those who do not use an ARC/INFO compatible Geographic Information System. Each set contains an image of a geologic map sheet and the accompanying explanatory pamphlet. There is a set available in PostScript format, and another in Acrobat PDF format (see sections below). Those who have computer capability can access the plotfile packages in either of the two ways described below; however, these packages do require winzip utilities to access the plot files. Requests for a CD copy of the digital database or plotfiles can be made by sending a blank CD-R or CD-RW with requests and return address to: Database Coordinator, U.S. Geological Survey, 345 Middlefield Road, M/S 975, Menlo Park, CA 94025. Plot files can also be acquired online at http://geopubs.wr.usgs.gov/open-file/of01-424.

Those without computer capability can obtain plots of the map files through USGS Plot-On-Demand service for digital geologic maps. To obtain plots of the map sheet and accompanying pamphlet, contact the USGS Information Services office at the following address: U.S. Geological Survey Information Services, Box 25286, Federal Center, Denver, CO 80225-0046. Or by phone (303)202-4200, fax (303)2024695, or by email: infoservices@usgs.gov. Be sure to include the map reference OF 01-424.

\section{DATABASE CONTENTS}

This digital database package consists of the geologic map database and supporting data including base maps, map explanation, geologic description, and references. A second package consists of PostScript plot files of a geologic map and geologic description. The third package contains PDF files of a geologic map and geologic descriptions.

\section{Digital Database Package}

The first package is composed of geologic map database files for southern and northern portions of lower Comb Wash. Files with the designation 'cwn' have the base map Bluff Northwest Quadrangle. Files with the designation 'cws' have the base map Bluff Southwest Quadrangle. The coverages and their associated INFO directory have been converted into ARC/INFO export files. These export files are uncompressed and are easily handled and compatible with some Geographic Information Systems other than ARC/INFO. The export files included are: 


$\begin{array}{lll}\text { cwn_drain.e00 } & \text { cwn_drain } & \text { Drainages and annotation } \\ \text { cwn_anno.e00 } & \text { cwn_anno } & \text { Annotation for poly coverage } \\ \text { cwn_poly.e00 } & \text { cwn_poly } & \text { Depositional contacts and geologic units } \\ \text { cwn_profile.e00 } & \text { cwn_profile } & \text { Location of stratigraphic description } \\ \text { cwn_xsect.e00 } & \text { cwn_xsect } & \text { Location of geomorphic cross-sections } \\ \text { cws_anno.e00 } & \text { cws_anno } & \text { Annotation for poly coverage } \\ \text { cws_drain.e00 } & \text { cws_drain } & \text { Drainages and annotation } \\ \text { cws_poly.e00 } & \text { cws_poly } & \text { Depositional contacts and geologic units } \\ \text { cws_xsect.e00 } & \text { cws_xsect } & \text { Location of geomorphic cross-sections }\end{array}$

The database package also contains the following export files with extraneous data used in the construct of the database:

$\begin{array}{lll}\text { geolin.lut.e00 } & \text { geolin.lut } & \text { cwn_poly and cws_poly line lookup table } \\ \text { geo.lin.e00 } & \text { geo.lin } & \text { lineset } \\ \text { cw_poly.lut.e00 } & \text { cw_poly.lut } & \text { cwn_poly and cws_poly lookup table } \\ \text { geofont.txt.e00 } & \text { geofont.txt } & \text { textset used for all annotation } \\ \text { color524.shd.e00 } & \text { color524.shd } & \text { 524 color shadeset } \\ \text { cw_import.aml } & \text { AML to convert all export files in the database to coverages and graphic files }\end{array}$

Postscript Plotfile Package

The second digital data package available contains the Post Script images described below:

cw_map.eps: Encapsulated Post Script file plottable file containing complete map composition with geology, Comb Wash and tributaries, annotation, correlation of map units and legend of symbols and lines.

cw_map.ai: Adobe Illustrator file containing complete map composition with geology, Comb Wash and tributaries, annotation, correlation of map units and legend of symbols and lines.

cw_pamph.doc: An MS word document file of the report containing detailed unit descriptions and geological information, plus references sited.

cw_readme.doc: An MS word document file of this report.

\section{PDF file Description}

cw_map.pdf: Geologic map, correlation of map units, legend of symbols and lines and key to geologic units

cw_pamph.pdf: Report containing detailed unit descriptions and geological information.

cw_readme.pdf: A pdf version of this report

The PDF files were created from corresponding .ps files and are compatible with Adobe Acrobat version 3.0 and higher.

\section{ACCESSING DATABASE CONTENTS}

\section{Arc/Info Export files}

Arc export files can be converted to their proper ARC/INFO format using the ARC command 'import' with the option proper for the format desired. To ease conversion and preserve naming convention, an AML is enclosed that will convert all the export files in the database to coverages and graphic files and will also create an associated INFO directory. From the ARC command line type:

Arc: \&r cw_import.aml 
Arc export files can be read by other Geographic Information Systems. Refer to your documentation for proper procedure for retrieval of data.

\section{Post Scripts and Portable Document Files}

These files are packaged separately. PDF files come as is and can be downloaded or copied directly to your hard drive with no conversion aside from opening the file from Adobe Acrobat. The Post Script documents are zipped and compressed to a smaller file size. They can be decompressed using gzip.

\section{DATABASE SPECIFICS}

Procedure Used

Stable base-maps were digitized at the USGS Flagstaff Field Center using an Altek Datatab Proline AC32 digitizer. A tic file was created and projected into UTM zone 12. Lines, points, polygons and annotation were edited using ARCEDIT. ARC/INFO generated the following RMS error report after transforming the coverage from digitizer units to real world coordinates:

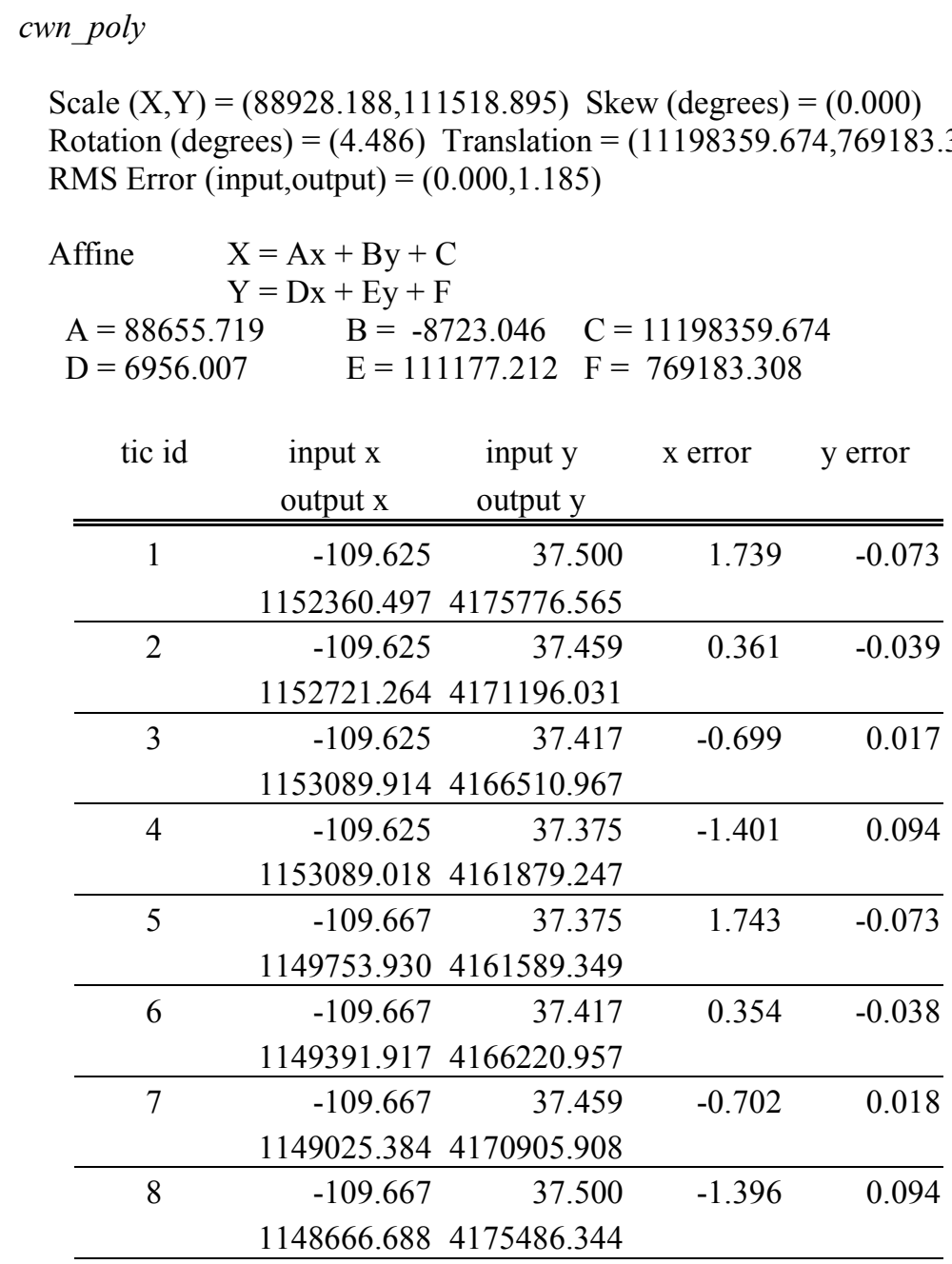




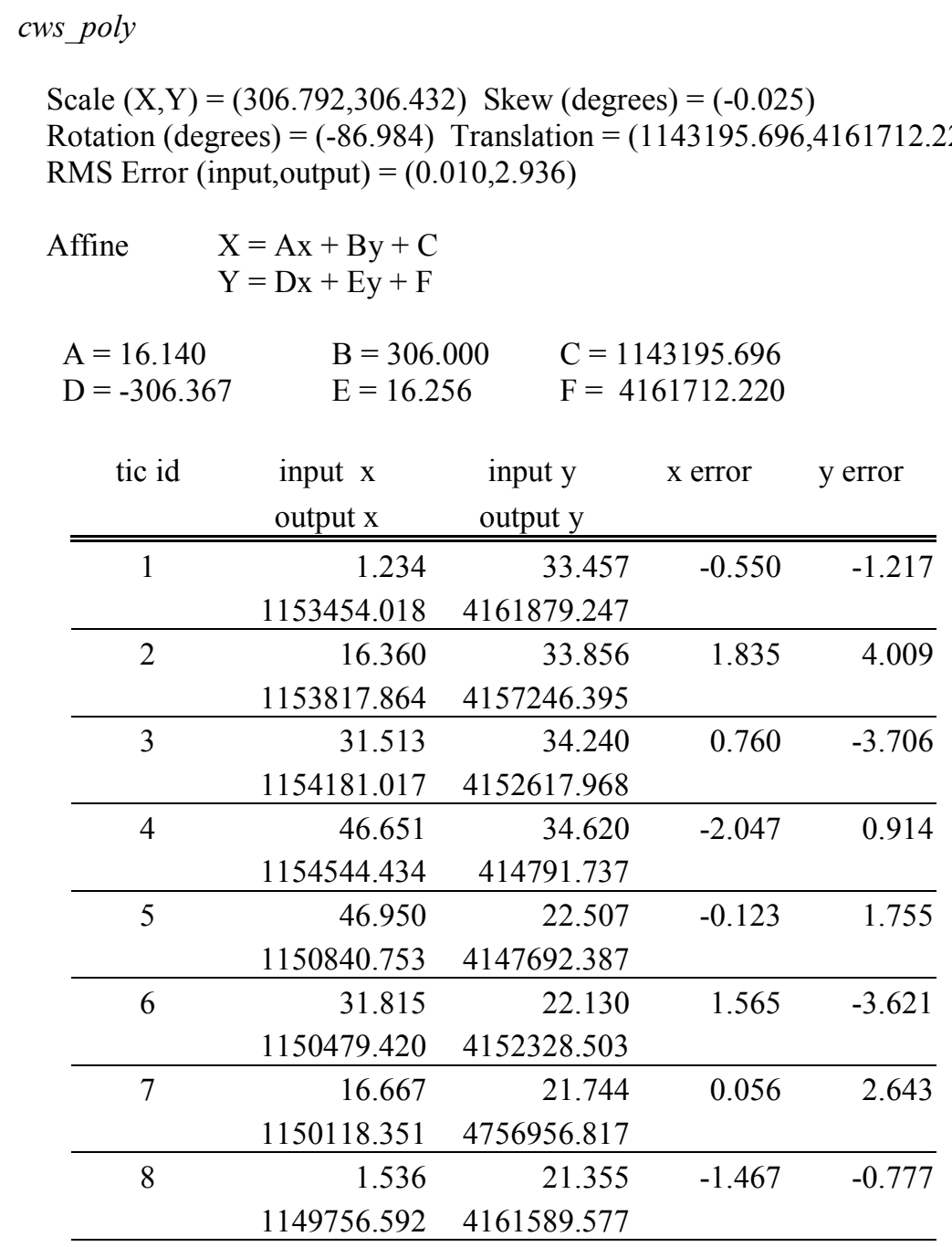

Map Projection

$\begin{array}{ll}\frac{\text { Parameter }}{\text { Projection }} & \text { Description } \\ \text { Units } & \text { meters on the ground } \\ \text { Zone } & 12 \\ \text { Datum } & \text { NAD27 }\end{array}$

The content of the geologic database can be described in terms of the lines and the areas that compose the map. Descriptions of the database fields use the terms explained below

\section{Database Fields}

$\begin{array}{ll}\text { Parameter } & \text { Description } \\ \text { Item name } & \text { name of database field } \\ \text { Width } & \text { maximum number of characters or digits stored } \\ \text { Output } & \text { output width } \\ \text { Type } & \text { B=binary integer; F=binary floating point number; I=ASCII integer; } \\ & \mathrm{C}=\text { ASCII character string }\end{array}$


The arcs are recorded as strings of vectors and described in the arc attribute table (AAT). They define the boundaries of the map units, map boundaries and other linear features in cwn_poly and cws_poly. These distinctions and the geologic identities of the boundaries are stored in the LTYPE field according to their line type.

Arc Attribute Table Definitions

$\begin{array}{cccccc}\text { COLUMN } & \text { ITEM NAME } & \text { WIDTH } & \text { OUTPUT } & \text { TYPE } & \text { N. DEC } \\ 1 & \text { FNODE \# } & 4 & 5 & \text { B } & -- \\ 5 & \text { TNODE \# } & 4 & 5 & \text { B } & -- \\ 9 & \text { LPOLY \# } & 4 & 5 & \text { B } & -- \\ 13 & \text { RPOLY \# } & 4 & 5 & \text { B } & -- \\ 17 & \text { LENGTH } & 8 & 18 & \text { F } & 5 \\ 25 & \text { CWN_POLY\# } & 4 & 5 & \text { B } & -- \\ 29 & \text { CWN_POLY-ID } & 4 & 5 & \text { B } & -- \\ 33 & \text { LTYPE } & 35 & 35 & \text { C } & --\end{array}$

Description of AAT Items

$\begin{array}{ll}\text { ITEM } & \text { DESCRIPTION } \\ \text { FNODE \# } & \text { Starting node of an arc } \\ \text { TNODE } \# & \text { Ending node of the arc } \\ \text { LPOLY \# } & \text { Polygon to the left of the arc } \\ \text { RPOLY \# } & \text { Polygon to the right of the arc } \\ \text { LENGTH } & \text { Length of the arc in meters } \\ \text { CWN_POLY \# } & \text { Unique internal number } \\ \text { CWN_POLY-ID } & \text { Unique identification number } \\ \text { LTYPE } & \text { Line type }\end{array}$

Domain of Line Types recorded in LTYPE field

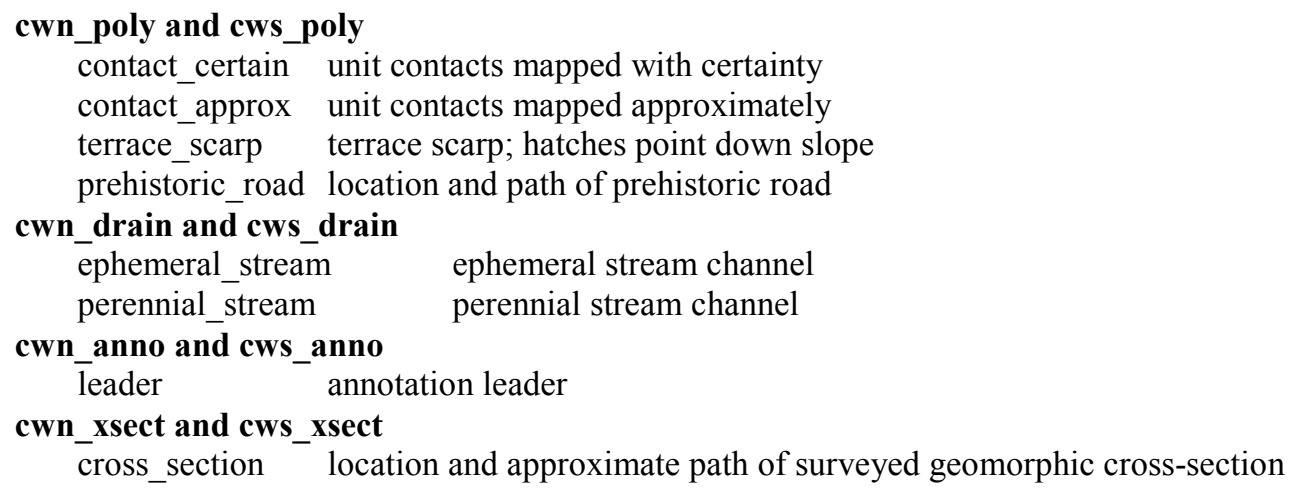

\section{POLYGONS}

Map units (polygons) are best described in the cwn_poly and cws_poly polygon attribute tables (PAT). This identifies the units recorded in the PTYPE field by map label. Individual map units are described more fully in the accompanying text. 
Definition of polygon attribute table:

$\begin{array}{cccccc}\text { COLUMN } & \text { ITEM NAME } & \text { WIDTH } & \text { OUTPUT } & \text { TYPE } & \text { N. DEC } \\ 1 & \text { AREA } & 8 & 18 & \text { F } & 5 \\ 9 & \text { PERIMETER } & 8 & 18 & \text { F } & 5 \\ 17 & \text { CWN_POLY\# } & 4 & 5 & \text { B } & -- \\ 21 & \text { CWN_POLY-ID } & 4 & 5 & \text { B } & -- \\ 25 & \text { PTYPE } & 6 & 6 & \text { C } & --\end{array}$

Description of item name

\section{ITEM NAME \\ AREA \\ PERIMETER \\ CWN_POLY\# \\ CWN_POLY-ID \\ PTYPE}

\author{
DESCRIPTION \\ Area of polygon in square metes \\ Perimeter of polygon in meters \\ Unique internal number \\ Unique identification number \\ Unit name
}

Domain of PTYPE (map units)

af, ta, mct, bct, t3, t2, t1, col, Trc , Trm, Pcm, mfp, st

$\mathrm{P}$ represents permian strata, Tr represents triassic strata, $\mathrm{t} \#$ represent Quaternary terraces. Polygons were assigned colors from the shadeset COLOR524.SHD and are related to the CWPOLY.LUT lookup table.

\section{POINTS}

Geologic point feature information (stratigraphic profile locations) is recorded as coordinate data with related information. this information is described in the cwn_profile point attribute table (PAT).

Definition of point attribute table

$\begin{array}{cccccc}\text { COLUMN } & \text { ITEM NAME } & \text { WIDTH } & \text { OUTPUT } & \text { TYPE } & \text { N. DEC } \\ 1 & \text { AREA } & 8 & 18 & \mathrm{~F} & 5 \\ 9 & \text { PERIMETER } & 8 & 18 & \mathrm{~F} & 5 \\ 17 & \text { CWN_PROFILE\# } & 4 & 5 & \mathrm{~B} & -- \\ 21 & \text { CWN_PROFILE-ID } & 4 & 5 & \mathrm{~B} & -- \\ 25 & \text { ID-NO } & 6 & 6 & \mathrm{C} & --\end{array}$

Description of item names

\begin{tabular}{ll}
\multicolumn{1}{|c}{ ITEM } & DESCRIPTION \\
AREA & Degenerate area of a point \\
PERIMETER & Degenerate perimeter of a point \\
CWN_POINT\# & Unique internal number \\
CWN_POINT-ID & Unique identification number \\
ID-NO &
\end{tabular}




\begin{abstract}
ANNOTATION
cwn_anno and cws_anno contain the annotation for the features contained in cwn_poly and cws_poly.

\section{SPATIAL RESOLUTION}

Use of this digital geologic map database should not violate the spatial resolution of the data. Although the digital form of the data removes the constraint imposed by the scale of the paper map, the detail and accuracy inherent in map scales are also present in the digital data. This database was created and edited at the scale of 1:12,000, which means that higher resolution data are generally not present. Plotting at scales larger than 1:12,000 will not yield greater real detail but may reveal fine-scale irregularities below the intended resolution.
\end{abstract}

